\author{
ARTIGOS
}

\title{
A TRIPLICIDADE DO ESPAÇO E DAS PRÁTICAS COTIDIANAS DE MOBILIDADE PARA O ESTUDO DA FRAGMENTAÇÃO SOCIOESPACIAL ${ }^{1}$
}

\author{
Jean Legroux ${ }^{2}$ \\ Universidade Estadual Paulista
}

Enviado em 7 dez. 2020 | Aceito em 11 mai. 2021

Resumo: O presente artigo pretende demostrar a relevância de um conceito amplo de mobilidade cotidiana para o estudo dos processos de fragmentação socioespacial no contexto urbano. Para este propósito, a ideia lefebvriana de triplicidade do espaço permite propor uma visão ampla da mobilidade cotidiana, desde as estruturas e infraestruturas e modelos de mobilidade, até as práticas individua is, que se articulam com a análise dos processos de fragmentação socioespacial. A mobilidade, instrumento de fragmentação, de alienação e de exclusão, pode também revelar seu potencial de resistência contra o poder hegemônico. A partir de um conjunto de dados coleta dos, de experiências e pesquisas realizadas ao longo de dez anos no tema da mobilidade, a presente proposta trará principalmente o contexto brasileiro para sustentar o argumento principal.

Palavras-Chave: Mobilidade cotidiana; Fragmentação socioespacial; Triplicidade do espaço; Práticas espaciais; Cotidiano.

\section{THE TRIPLICITY OF SPACE AND EVERYDAY MOBILITY FOR THE STUDY OF SOCIOSPATIAL FRAGMENTATION}

Abstract: This article aims to discuss the relevance of a broad concept of daily mobility by studying socio-spatial fragmentation processes in urban contexts. For this purpose, we applied the Lefebvrian idea regarding the triplicity of space. This concept allows us to propose a substantial vision of daily mobility from structures, infrastructures, and models. Additionally, it also provides an understanding of individual practices who articulate themselves with the analysis of socio-spatial fragmentation. The mobility can be interpreted as an instrument of fragmentation, alienation, and exclusion; however, it could also reveal its potential for resistance against hegemonic powers. Based on a compilation of data on the mobility question, from previous research and experiences collected through ten years, the current article is based on the Brazilian context to support our main argument.

Keywords: Daily Mobility; Socio-spatial fragmentation; Triplicity of space; Spatial practices; Everyday life.

\section{LA TRIPLICITÉ DE L’ESPACE ET LA MOBILITÉ QUOTIDIENNE POUR L'ÉTUDE DE LA FRAGMENTATION SOCIO-SPATIALE}

Résumé: Cet article prétend démontrer la pertinence d'un concept ample de mobilité quotidienne pour l'analyse des processus de fragmentation socio-spatiale dans le contexte urbain. Pour ce faire, l'idée lefebvrienne de triplicité de l'espace permet de proposer une vision ample de la mobilité quotidienne, que ce soit à partir des structures, infrastructures et modèles de mobilité, ou en termes de pratiques individuelles, qui s'articulent avec l'analyse des processus de fragmentation socio-spatiale. La mobilité, instrument de fragmentation, d'aliénation et d'exclusion, peut également révéler son potentiel de résistance contre le pouvoir hégémonique. À partir d'un ensemble de données collectées, d'expériences et de recherches réalisées au long des dix dernières années dans le thème de la mobilité, la proposition, ici, se basera principalement sur le contexte brésilien pour soutenir l'argument principal.

Mots-clés: Mobilité quotidienne ; Fragmentation socio-spatiale ; Triplicité de l'espace ; Pratiques spatiales ; Quotidien.

1. Agradeço a Dra. Ana Luiza Nabuco pela revisão do texto. Os agradecimentos também são dirigidos à Fundação de Amparo à Pesquisa do Estado de São Paulo (FAPESP) pelo financiamento do projeto FragUrb (Processo n 2018/07701-8), ao qual vincula-se o autor com a bolsa de pós-doutorado (processo n.2019/04664-7).

2. Doutor em Geografia e em Planejamento Urbano e Regional. Pós doutorando no programa de pós-graduação em Geografia da UNESP de Presidente Prudente (SP). ORCID: http://orcid.org/0000-0002-3811-4180. E-mail: jean.legroux@unesp.br. 


\section{Introdução}

Nas últimas décadas, a fragmentação socioespacial tornou-se um conceito para a intepretação das mudanças urbanas - em termos de formas e de conteúdos - que vêm ocorrendo desde os anos 1970 nas cidades latino-americanas (VIDAL, 1995; DUHAU e GIGLIA, 2016; PRÉVÔT-SHAPIRA, 2001; SPOSITO e GÓES, 2013). A fragmentação socioespacial daria conta de explicar, conjuntamente, o acirramento de processos mais antigos (como a segregação socioespacial, o afastamento e a periferizacão das classes populares, a diferenciação socioespacial etc.) e de outros um pouco mais recentes, como a autossegregação, a multiplicação da centralidade ou a policentralidade, a importância do consumo e a "transformação do sentido e do conteúdo de vários espaços públicos", com a emergência, por exemplo, de "espaços públicos de uso coletivo privado" (SPOSITO, 2019).

O que teria se perdido é uma visão e uma lógica unitária da cidade (PRÉVÔT-SCHAPIRA, 2001), deixando lugar a uma lógica fragmentária, que se observa de forma mais evidente no espaço, com um campo lexical que expressa rupturas e fechamentos nos espaços urbanos: mosaicos, arquipélagos, fragmentos, pedaços, ilhas, barreiras, "cidade de muros" (CALDEIRA, 2000), "espaços fechados" (HIDALGO e BORSDORF, 2005; SPOSITO e GÓES, 2013;), "vazios urbanos" (SANTOS, 1990), "mosaicos de fragmentos não conectados" (SÉGUIN, 2011). Os processos fragmentários implicam uma redefinição do par público-privado e expressam-se em diversas escalas, tanto em metrópoles (SANTOS, 1990) quanto em cidades médias (LINARES, 2009).

Embora seja essencial apreender a fragmentação socioespacial através das suas formas espaciais, do seu lado estrutural, no entanto, o estudo do cotidiano urbano e das práticas espaciais é também imprescindível para entender de forma mais abrangente o conteúdo fragmentário do espaço, das relações sociais e das práticas. A análise do cotidiano é complexa porque este envolve todas as esferas de vida dos indivíduos e classes sociais no tempo e no espaço. Ou seja, a ideia ou o conceito de fragmentação socioespacial situa-se para além de explicações exclusivamente centradas no tema da moradia-trabalho, integrando outras dimensões (que correspondem a espaços específicos) que explicam - e nas quais se expressam - os processos fragmentários, como o lazer, a mobilidade e o consumo. Cabe dizer que os processos que ocorrem na mobilidade são ligados ao acirramento da chamada sociedade de consumo, em que a figura do shopping center, por exemplo, expressa e reforça o processo de constituição de policentralidade (SOUSA, 2019; GÓES e SPOSITO, 2016).

A análise do cotidiano urbano para entender os processos de fragmentação socioespacial implica compreender as suas principais dimensões, isto é, o que ocupa a maioria do tempo dos indivíduos nas sociedades capitalistas: o trabalho, a moradia, o lazer, o consumo e a mobilidade. Apreender as práticas espaciais e o cotidiano urbano através destas categorias pode permitir enxergar os processos fragmentários além das formas urbanas e configura-se como um método. Pode se vislumbrar, de certa forma, uma fragmentação do próprio cotidiano urbano, no sentido da negação das possibilidades libertadoras do urbano vislumbrada por Lefebvre (1970) e fortemente ligada à modernidade (LEFEBVRE, 1968).

A mobilidade é, à primeira vista, o nexo entre as diferentes dimensões cada vez mais fragmentadas da vida cotidiana (habitar, consumo, lazer, trabalho, relações, educação, saúde etc.) e envolve tempos (do corpo, do deslocamento, ou ainda aquele necessário para financiar os deslocamentos) e elementos espaciais (distâncias, barreiras físicas e simbólicas). Ao abordar a mobilidade cotidiana através da proposta teórica de triplicidade do espaço de Lefebvre (1974) colocado em relação com os três pilares da definição da mobilidade de Kaufmann, Bergman e Joye (2004) - o objetivo principal do presente artigo consiste em demostrar como esta abordagem ampla da mobilidade e das práticas cotidianas de mobilidade podem enriquecer o debate e o método para 
capturar os processos de fragmentação socioespacial. Desta forma, este artigo não se baseia em um caso empírico concreto e único - como uma cidade ou um bairro, ou um conjunto de alguns indivíduos - mas utiliza, pontualmente, resultados empíricos e análises produzidos ou coletados pelo autor na última década.

\section{O espaço concebido: mobilidade cotidiana, modelo rodoviarista e lógica fragmentária}

O espaço concebido, primeiro pé da triplicidade do espaço, corresponde às representações do espaço, isto é, ligado à ordem imposta - incluído em termos de conhecimentos, signos, códigos -, e às relações de produção e de reprodução. Diz respeito ao espaço dominante em uma sociedade, ou seja, ao espaço pensado e construído pelo poder político, econômico (e hoje, financeiro), através dos planejadores, urbanistas, tecnocratas. Em termos de mobilidade, este espaço pode relacionar-se com o primeiro pilar da definição do conceito de motility, proposto por Kaufmann, Bergman e Joye (2004): a acessibilidade. Nos termos propostos pelos autores, esta última depende das opções (meios de transporte e de comunicação, equipamentos acessíveis) e das condições (de acesso a estas opções em termos de localização, logística e outros impedimentos). Segundo Lefebvre (1974), o primado do concebido sobre o vivido faz desaparecer à prática espacial, ou, em outros termos, poderíamos dizer, desintegra a sua unidade, a fragmenta. Evidentemente, o espaço concebido implica uma abordagem atenta às estruturas, às consequências do que foi planejado e construído, o que, para o tema da mobilidade, poderia ser pensado pelo viés da opressão, do que é imposto: as localizações residenciais, as ofertas em termos de infraestruturas e, portanto, em termos de tempos de trajetos, de custo do transporte, de acessibilidade à cidade, ou ainda em termos de total imobilidade.

\section{O conceito de mobilidade cotidiana e a estrutura das desigualdades}

O conceito de mobilidade é polissêmico. Cabe primeiramente distinguir a mobilidade cotidiana, as viagens (o conjunto de deslocamentos inter-regionais ou internacionais com uma intenção de retorno a curto prazo), a mobilidade residencial e a migração (entendida como a instalação em uma outra região ou em outro país, sem intenção de retorno a curto prazo) (KAUFMANN, 1999). Evidentemente, estes tipos de mobilidade interagem: por exemplo, a mobilidade residencial terá impactos sobre a mobilidade cotidiana.

Trataremos, aqui, da mobilidade cotidiana que se refere, primeiramente, aos deslocamentos diários de pessoas entre seus domicílios e outras esferas da vida cotidiana (trabalho, lazer, saúde, consumo, relações sociais e familiares, educação, oportunidades etc.). Compreendida assim, como um deslocamento físico, a mobilidade cotidiana é sinônimo de mobilidade física, de mobilidade espacial, de mobilidade urbana, ou ainda, de deslocamentos pendulares (geralmente entendidos como os deslocamentos casa-trabalho).

A mobilidade cotidiana é uma condição essencial do acesso à cidade e às suas amenidades, e, portanto, do grau de integração/fragmentação das pessoas na sociedade e no espaço. Neste sentido, a literatura identifica uma correlação entre mobilidade espacial (cotidiana) e mobilidade social (ORFEUIL, 2004), entre mobilidade cotidiana e justiça espacial (LEIBLER e MUSSET, 2010) e entre mobilidade e direito à cidade (FIX, 2015). Seja de forma ascendente ou descendente, a mobilidade cotidiana é um vetor essencial da mobilidade social. Assim, analisar a mobilidade cotidiana e as condições de acesso aos serviços de transporte é um dos caminhos para compreender as diversas relações que existem entre pobreza e dificuldades de deslocamentos (DIAZ OLVERA, PLAT e POCHET, 2005). Ou seja, tem sido reconhecido o fato de que: 
enquanto eram dissociados no campo científico, as mobilidades, no sentido social, e os deslocamentos físicos são doravante fortemente articulados. [...] Nesta perspectiva, o acesso à mobilidade não é igualmente distribuído entre as classes sociais e constitui um fator potente de exclusão3 (FLONNEAU e GUIGUENO, 2009, p. 13).

Para a realidade brasileira, diversos autores também enxergam a mobilidade como uma dimensão essencial do combate à pobreza e às desigualdades, ou a imobilidade como fator de reprodução das desigualdades (GOMIDE 2003, 2006; VASCONCELLOS, 2014; LEMOS, SANTOS e SILVA, 2004; IPEA, 2011; PEREIRA, BANISTER, SCHWANEN e WESSEL, 2019).

Desta forma, a mobilidade pode tanto representar um meio de combater as desigualdades, de alcançar oportunidades e viver a cidade em seu sentido pleno, quanto pode ser fator ou expressão de processos desiguais e de fragmentação socioespacial. As restrições em termos de mobilidade representam frequentemente um entrave ao acesso à cidade, ao direito à cidade e a justiça espacial (SOJA, 2010; LEGROUX, 2016).

Os sistemas de mobilidade, nas cidades, articulam-se com a ordem dominante de produção do espaço, isto é, o espaço concebido. No campo da mobilidade cotidiana, a estrutura social, econômica e espacial das cidades determina os tempos de viagens, as distâncias entre o lugar de moradia e trabalho (e outros espaços), mas também a qualidade do transporte, os meios accessíveis etc. Para entendermos melhor de que forma o espaço concebido cria, através das condições de mobilidade, processos de segregação e de fragmentação socioespacial, abordamos o "modelo rodoviarista" em vigor nas realidades urbanas brasileiras, fruto das políticas dos diferentes níveis de governo e da evolução do sistema econômico e do modelo de produção capitalista.

\section{Modelo rodoviarista, crise da mobilidade e fragmentação socioespacial}

Na realidade urbana brasileira, nas metrópoles - mas não somente ${ }^{4}$ - o "modelo rodoviarista" refere-se à constituição de sistemas urbanos, em que predominam as infraestruturas viárias (pontes, túneis, rotatórias, viadutos, anéis rodoviários, vias expressas, contornos, retornos e estacionamentos) e os modos motorizados, isto é, o automóvel e as motocicletas em termos de transporte individual e os ônibus, principalmente, em termos de transporte coletivo. Este sistema participa de morfologias urbanas segregadas e fragmentadas, porque, paradoxalmente, estas infraestruturas que "conectam" fragmentos, criam inúmeras barreiras físicas e linhas que cortam literalmente o espaço físico.

O sistema rodoviarista de mobilidade, em que o automóvel tem um lugar de destaque, participa evidentemente de uma forma de produção do espaço, em curso há décadas, nas cidades brasileiras, como Santos (1990) já o notou em seu livro sobre São Paulo intitulado Metrópole corporativa fragmentada, com um acirramento da periferizacão em termos de projetos públicos de moradias populares distantes do centro, a multiplicação de vazios urbanos e o crescente uso do automóvel. 0 modelo rodoviarista, com a multiplicação do "efeito túnel" e do "efeito de confinamento" (JIRÓN, 2010), se materializa por inúmeras vias e trajetos que são dedicados apenas à circulação. Nota-se,

3 Tradução própria de: « alors qu'ils étaient disjoints dans le champ scientifique, les mobilités, au sens social, et les déplacements physiques sont désormais fortement articulés [...] Dans cette perspective, l'accès à la mobilité n'est pas également distribué parmi les classes sociales et constitue un puissant facteur d'exclusion ».

40 modelo rodoviarista atinge hoje em dia todos os tipos de cidades e o urbano em geral. Por exemplo, ao analisar as mudanças do centro histórico e as práticas espaciais dos habitantes de Presidente Prudente (SP), Góes e Sposito (2016), também dão ênfase ao papel do automóvel nestes processos, inclusive com relação à aparição de um shopping center. 
assim, a intensificação dos processos fragmentários do ponto de vista físico: por exemplo, uma via rápida pode conectar mais rápido duas centralidades, mas dificultar a acessibilidade de outros bairros no meio do trajeto, ou a trafegabilidade dos pedestres.

Do ponto de vista da fragmentação socioespacial, o modelo rodoviarista tem impactos nas formas urbanas fragmentadas, isto é, na intensificação de rupturas, descontinuidades, fragmentos, da dispersão urbana. Isto é associado a um modo de vida, em que a lógica dominante (do espaço concebido) definiu a mobilidade como sendo a conexão entre áreas fortemente especializadas e separadas: da casa ao trabalho, do trabalho à academia, da academia para o shopping, do shopping para o clube etc. Neste sentido, a homogeneização da sociedade traduz-se por uma diferenciação e separação crescente dos lugares (LEFEBVRE, 1968, 1974). A fragmentação da mobilidade também expressa uma fragmentação social no movimento, com a criação de diferentes circuitos separados, para os pobres, os ricos, as mulheres, os idosos etc. (JIRÓN, 2010).

Dentre outros fatores ${ }^{5}$, a crise da mobilidade, nas cidades brasileiras, é resultado deste modelo de mobilidade rodoviarista - intrinsicamente ligado ao modelo ou regime urbano neoliberal, que organiza o espaço e o sistema de transporte conforme os seus objetivos - com o abandono progressivo dos investimentos em infraestruturas de transporte público dito de massa, ou de alta capacidade, como o metrô, os trens, os tramways etc. ${ }^{6}$ Tomando o exemplo do Rio de Janeiro, enquanto o bonde desaparece, deixando lugar ao transporte por ônibus a partir dos anos 1950, notase, a partir dos anos 1980, investimentos insuficientes em ferroviárias - trens e metrôs (ABREU, 1996; BEYER, 2011). Nos anos 1990, a degradação do transporte coletivo - junto com o aumento dos automóveis piora o transporte por ônibus - cria dois tipos de fuga para os usuários: por cima, com a aquisição de um meio individual motorizado (para quem pode), e por baixo, caracterizada pela exclusão e a pauperização de algumas categorias sociais que se encontram em situações de mobilidade muito limitadas, transferindo-se do transporte coletivo para o andar a pé e a bicicleta, ou até para uma completa imobilidade.

Gráfico 1 - Distribuição das viagens urbanas no município do Rio de Janeiro (1950 e 2005)

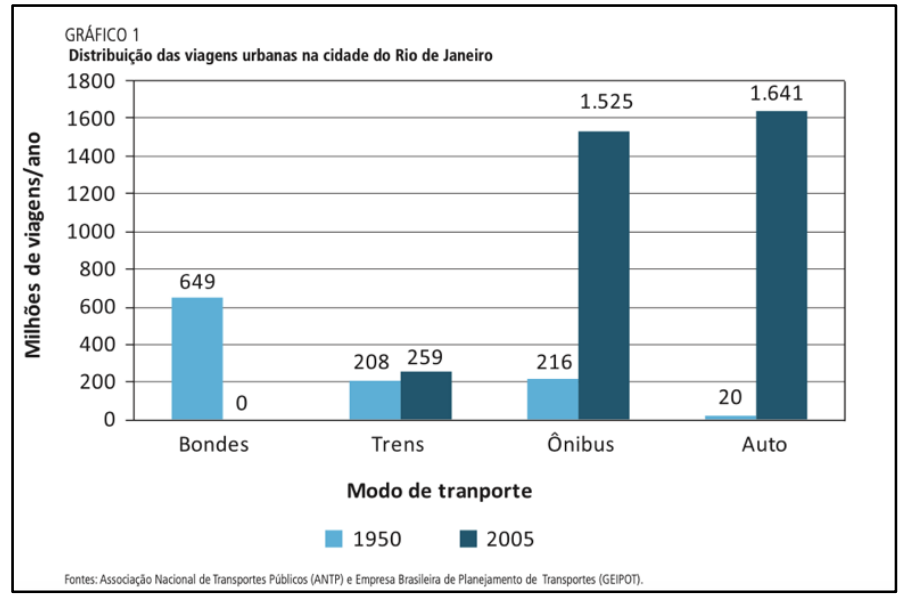

Fonte: Pereira, Galindo e Vasconcellos (2011)

5 Neste sentido, poderia, também, focar-se nas relações entre grandes empresas de transporte (de lógica privada) com os governos locais, ou, ainda, nas evoluções da indústria ao nível nacional e mundial.

6 Investimentos recentes com a Copa do Mundo e Olimpíadas foram insuficientes para reverter o quadro (LEGROUX, 2016; 2019). 
Assim, de 1950 a 2005, registra-se o desaparecimento dos bondes, uma explosão do transporte por ônibus, uma explosão dos automóveis e, mais recentemente, das motocicletas (ver Gráfico 1). Segundo Pereira, Galindo e Vasconcellos (2011, p.2):

a cidade mudou de uma mobilidade essencialmente pública e movida à eletricidade (o bonde e o trem) para outra que mistura a mobilidade pública e privada e depende essencialmente de combustíveis fósseis.

O sistema rodoviarista, no Brasil, tem uma longa história (VASCONCELLOS, 2005, LEGROUX, 2016). Aqui, focaremos apenas nas duas últimas décadas. Desde os anos 2000, a estratégia da indústria automobilística brasileira visando a produção de carros de pequenas cilindradas (o famoso motor "1.0") acelerou a generalização do automóvel como meio de transporte. As empresas estrangeiras também atuaram no sentido de produzir veículos "low-costs" adaptados à demanda local. Desta forma, de 2001 a 2012, a taxa de motorização dos municípios brasileiros de mais de 500.000 habitantes passou de 18,5 a 31,9/100 habitantes (RIBEIRO e RODRIGUES, 2013). No mesmo período, nas quinze principais regiões metropolitanas do país, a frota de automóveis aumentou em mais de 90\% (um aumento de 11,4 milhões de veículos) (Ver llustração 2). E esta tendência se intensifica: segundo a Associação Nacional dos Detrans (AND, 2017), o Brasil possuía em 2017 um automóvel para cada 4,4 habitantes (isto é, um total de 45,4 milhões de automóveis), proporção que era de 7,4 habitantes por carro em 2007.

Gráfico 2 - Crescimento das frotas de automóveis em 15 regiões metropolitanas brasileiras principais (em \%) (2001-2012)

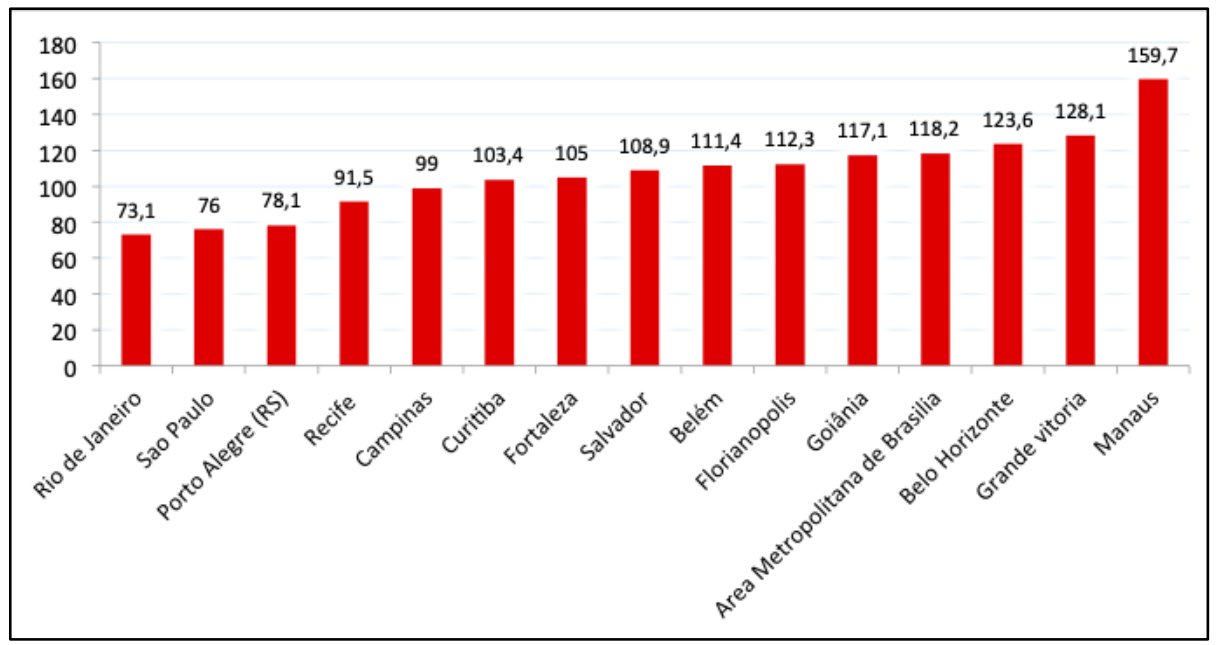

Fonte: Ribeiro e Rodrigues (2013), a partir de dados do RENAVAN (Registro Nacional de Veículos Automotores) e do DENATRAN (Departamento Nacional de Trânsito)

Com relação à fragmentação socioespacial, este modelo corresponde à exaltação de uma solução individual (o carro ou a motocicleta) para enfrentar as distâncias, ou a inexistência ou ineficiência do transporte público. Ou seja, este modelo reforça a redefinição do par público-privado a favor deste último, tanto pelas práticas que pelo consumo de parcelas gigantescas de potenciais espaços públicos. Concretamente, esta crise da mobilidade caracteriza-se por um aumento dos tempos de deslocamentos (com engarrafamentos quilométricos nas grandes cidades), da poluição e da precariedade em termos de conforto e da insustentabilidade dos custos do transporte. Em termos de insegurança, em 2016, foram registradas 23.000 mortes por acidentes de trânsito, em um total de 630.000 vítimas nos 533 municípios brasileiros de mais de 60.000 habitantes - com um custo 
total (e social) de 115,4 bilhões de reais (ANTP, 2017). Apesar da constatação da insustentabilidade deste modelo de mobilidade e dos avanços consideráveis obtidos por diversos movimentos ${ }^{7}$ em favor das mobilidades "suaves", a tendência de crescimento do transporte individual, contudo, segue vigente: de 2014 a 2017, o transporte individual registrou, nas cidades brasileiras de mais de 60.000 habitantes, uma crescimento de $7 \%$, enquanto o transporte coletivo e o transporte não-motorizado registraram, respectivamente, uma queda de $2,4 \%$ e de $2,8 \%$ (ANTP, 2017).

Com este forte crescimento do número de automóveis nas duas últimas décadas, os proprietários de automóveis, que eram, outrora, privilegiados (quando menos automóveis circulavam) são hoje em dia também claramente afetados na qualidade dos seus deslocamentos. Sistêmica, a crise da mobilidade cotidiana afeta todos os setores da sociedade, embora em intensidades diferentes. Assim, de forma paradoxal, a relativa democratização do automóvel a partir dos anos 2000, com o crescimento sem precedentes das frotas de carros e motocicletas, levou à acentuação da chamada "crise da mobilidade".

O modelo rodoviarista cria o seu espaço, favorável ao transporte individual motorizado: em 2003, nos municípios brasileiros de mais de 60.000 habitantes, os ciclistas dispunham apenas de 0,15\% do sistema viário, esta mesma porcentagem sendo de 0,02\% para os pedestres, e 0,11\% para os ônibus (VASCONCELLOS, 2014). Por falta de dados mais recentes, mesmo imaginando, como hipótese optimista, que estes modos (a pé, bicicleta e ônibus) disponham, cada um deles, de $5 \%$ do espaço viário, o privilégio dos modos rodoviários fica evidente ao olhar para a repartição modal. No mesmo universo, em 2017, 40\% das viagens foram realizadas a pé e 3\% de bicicleta. 0 transporte motorizado individual assumiu $29 \%$ das viagens (25\% de automóvel e $4 \%$ de motocicleta), enquanto, em termos de transporte coletivo, $24 \%$ das viagens são realizadas de ônibus, contra $4 \%$ para os trilhos ${ }^{8}$.

O espaço concebido da mobilidade cotidiana é o espaço das classes médias, da economia automobilística, dos três níveis de governo (federal, estadual, municipal), que frequentemente, nas escalas locais, mantêm laços fortes com o setor de transporte por ônibus. Em uma entrevista, ao abordar projetos de mobilidade em curso no Rio de Janeiro em 2012, Vasconcellos (atualmente presidente da comissão técnica de Meio Ambiente da ANTP - Agência Nacional de Transporte Público), afirmava:

Os projetos de transporte em curso no Rio de Janeiro seguem uma lógica elitista, como todas as políticas de transporte no Brasil [...] Barra da Tijuca é o Miami brasileira, onde a nova classe média se implantou [...]. Teve um processo de concentração de rendas, de formação da nova classe média, e de exclusão política. Esta nova classe média, que se formou no tempo do milagre brasileiro (final dos anos 1960 e durante os anos 1970), tem condição de comprar automóveis e possui responsabilidade na burocracia e a tecnocracia de Estado [...] Assistimos, assim, a criação das cidades da classe média (Eduardo A. Vasconcellos, entrevista conduzida pelo autor, no dia 25 de setembro de 2012).

Por mais que o espaço concebido da mobilidade seja o das classes altas e médias, estas são não obstante, afetadas pela crise da mobilidade, de acordo com a afirmação seguinte:

as classes médias não terão mais que uma sombra de poder, mais que uma migalha de riqueza, mas é em torno delas que o cenário se organiza. Seus 'valores', sua 'cultura' levam

\footnotetext{
7 Podemos pensar nos movimentos "Tarifa Zero" e em diversas associações de ciclistas urbanos, como a BH em Ciclo, em Belo Horizonte.

80 estudo ressalta que o transporte publico assume 36\% das viagens nos municípios maiores contra 19\% nos municípios menores, ao passo que o transporte individual (auto e moto) tem um comportamento mais estável (entre 27 e $31 \%$ ). 0 transporte não motorizado também aumenta quanto maior o município.
} 
vantagem ou parecem levar porque são 'superiores' aos da classe operária'. (LEFEBVRE, 1968, p.48)

Em termos de transporte coletivo, seja nas metrópoles ou em cidades menores, é preciso atentar para a predominância do ônibus enquanto meio de transporte coletivo, que implica, dentre outros fatores, a falta de investimentos em outros modais de transporte coletivo, tanto como os ferroviários (trem, metrô, veículo leve sobre trilho) quanto outras soluções (transporte marítimo, teleféricos, funiculares, por exemplo). O poder das empresas de ônibus explica-se, em parte, por suas estreitas relações com os poderes locais, principalmente municipais (MATELA, 2014; LEGROUX, 2016; RODRIGUES e BASTOS, 2016). Como ressaltam Pereira, Galindo e Vasconcellos (2011), de 1995 a 2011, as tarifas dos sistemas de ônibus, nos municípios de mais de 60.000 habitantes, aumentaram cerca de 60\% acima da inflação (medida pelo INPC), perdendo assim mais passageiros e instaurandose um círculo vicioso. Deste modo, a precariedade, a disponibilidade e o custo do transporte coletivo vêm acirrar as taxas de imobilidade, acentuando a fragmentação socioespacial ao dificultar a circulação e o acesso às áreas centrais, mas, também, ao "confinar" parcelas da população nos seus territórios.

Esta crise, que tem impactos consideráveis no cotidiano de grandes proporções de pessoas nas cidades brasileiras, participa dos processos de fragmentação socioespacial, dividindo os espaços do cotidiano, impedido o acesso à cidade e, como afirma Jirón (2010), fragmentando as próprias práticas de mobilidade e aumentando o "confinamento" em movimento. Neste sentido, importante lembrar que não é apenas o espaço que é fragmentado, mas os próprios tempos da vida cotidiana (JIRÓN e MANSILLA, 2014).

A mobilidade "falha" na missão de conectar e dar acessibilidade, reforçando a fragmentação socioespacial. Nos cotidianos urbanos, a crise da mobilidade implica, além das rupturas nas formas urbanas já abordadas, aumentos significativos dos tempos de deslocamentos, recordes de quilômetros de engarrafamentos, alta poluição do ar, degradação das condições de deslocamentos em termos de conforto e aumento da insegurança. Em vez de conectar os diferentes ambientes fragmentados, especializados, do cotidiano, a mobilidade cotidiana constitui-se um elemento fragmentador suplementar, um inimigo do tempo e do acesso à cidade. Neste contexto, cabe agora olhar para o espaço percebido, isto é, apreender as práticas reais de mobilidade, aquelas que se desenvolvem a partir do existente, parcialmente abordado aqui.

\section{O espaço percebido: práticas de mobilidade, competência e diferenciação}

Em outras palavras, uma vez abordadas as estruturas sociais e físicas, as infraestruturas de transporte disponíveis e a sua repartição no território, cabe ainda olhar para as práticas de mobilidade que se desenvolvem neste contexto. Nesse sentido, o espaço percebido leva ao estudo das práticas espaciais ligadas a mobilidade, isto é, a uma necessária análise empírica dos deslocamentos espaciais, do grau de apropriação e das estratégias dos indivíduos na sua "realidade quotidiana". A prática espacial cria o seu espaço dominando-o e apropriando-se o, e, no neocapitalismo, esta prática espacial associa "estreitamente no espaço percebido a realidade cotidiana (o emprego do tempo) e a realidade urbana (os percursos e redes que ligam os locais de trabalho, da vida 'privada', dos lazeres)" (LEFEBVRE, 1974, p.48). Associamos ao espaço percebido, o segundo pilar da definição do conceito de motility (KAUFMANN, BERGMAN e JOYE, 2004): a competência. Esta diz respeito, as aptidões e capacidades com relação ao acesso e a apropriação, que implica habilidades físicas, conhecimentos adquiridos e competências de organização. Para além das estruturas, da organização do espaço, das 
infraestruturas é preciso se atentar as aptidões e capacidades, em termos de habilidade física e de conhecimentos. Retomando o exemplo de Santos (1977, p. 86) - que cita Rudner (1973, p. 75), "dizer que uma casa é combustivel, obviamente, não é o mesmo que dizer que está ardendo em chamas" poderíamos dizer que não basta ter um sistema que permita os deslocamentos e o acesso, mas cabe também olhar para as capacidades de uso e apropriação dos indivíduos das opções disponíveis. Esta concepção dialoga com o espaço percebido (LEFEBVRE, 1974), ligado à prática espacial "real", à realidade do uso do tempo e dos percursos que ligam as diferentes atividades e esferas do cotidiano urbano. Esta visão convida a olhar as dinâmicas sociais e as relações de poder, além das possibilidades concretas de deslocamentos. Considerar este "princípio de realidade", permite entrar na dimensão simbólica e conflituosa da (i)mobilidade cotidiana e nas estratégias de diferenciação que nela se imprimem, e assim avançar na definição do conceito de mobilidade cotidiana.

\section{Os conceitos de capital espacial, de capital de mobilidade e de motility}

Apesar da conexão entre desigualdades, iniquidades e rupturas sociais, por um lado, e a dimensão espacial da mobilidade (ligada à localização residencial e à estrutura e repartição das atividades em um determinado ambiente urbano), por outro, muitos estudos sobre mobilidade ainda se limitam a estudar os deslocamentos de um ponto $A$ até um ponto $B$, às vezes em uma visão por demais tecnicista, quando a engenharia do transporte se confunde com a mobilidade cotidiana. A existência de modos de transporte (coletivos e individuais) - acessíveis (do ponto de vista econômico e físico) é evidentemente uma condição necessária da mobilidade cotidiana e, por consequência, do maior acesso à cidade.

Para entender as implicações da mobilidade cotidiana nos processos de fragmentação socioespacial, no entanto, é preciso uma compreensão do cotidiano urbano e das práticas espaciais. Neste sentido, alguns aportes teóricos a respeito do conceito de mobilidade permitem integrar à análise um enfoque nas estratégias individuais (e coletivas), nas relações de poder e de conflito e nas representações - isto é fornecer uma abordagem do simbólico.

Por este ângulo, os conceitos de capital de mobilidade e capital espacial ajudam a entender a mobilidade cotidiana em outros aspectos. O conceito de capital espacial pode ser definido como "o conjunto dos recursos acumulados por um ator, permitindo-Ihe tirar um benefício, em função da sua estratégia, do uso da dimensão espacial da sociedade" (LÉVY e LUSSAULT, 2003). Este conceito diz respeito à existência física de infraestruturas de transporte que permitem o deslocamento de indivíduos, mas, também, faz referência à capacidade de indivíduos usarem e apropriarem-se destes meios técnicos: i) em termos de poder econômico (de pagar o transporte), ii) em termos de acessibilidade para as pessoas com alguma deficiência, iii) em termos de capacidades pessoais de utilizar estes meios de transporte (saber ler um mapa por exemplo). Lembrando a ideia de "capabilities", de Sen (2011), esta questão da competência dos indivíduos - neste caso, por exemplo, de problemas de conhecimento do espaço, ou de dificuldades em ler - é social e tem impactos sobre a capacidade dos indivíduos de usar um meio de transporte (ORFEUIL, 2004).

O capital de mobilidade designa a capacidade variável de um individuo em realizar os deslocamentos desejados e impostos com o mínimo de obstáculos (financeiros, modais, simbólicos etc.). Designaria os recursos à disposição de um individuo para que possa satisfazer seus desejos e obrigações a partir de deslocamentos, com o mínimo de externalidades negativas. O capital de mobilidade é frequentemente avaliado através da taxa de mobilidade (número de deslocamentos por dia), de distâncias percorridas, ou, ainda, em termos de porcentagem dos gastos em transporte no orçamento individual ou familiar. 
As desigualdades de mobilidade cotidiana, não obstante, não podem se restringir ao cálculo da distância percorrida ou do número de deslocamentos diários. É preciso olhar para os sentidos e representações que estes dados escondem: por exemplo, uma baixa mobilidade pode expressar tanto uma situação periférica e limitada em termos de deslocamentos e oportunidades, quanto um modo de vida "caracterizado pela centralidade dos lugares de emprego e de residência e organizado em torno de relações de proximidade"9 (PAULO, 2006, p. 13). Uma advertência também notada por Kaufmann, Bergman e Joye (2004), para quem os estudos da mobilidade espacial tendem a focar-se nos movimentos no espaço e no tempo mais do que na interação entre os atores, as estruturas e os contextos. Ou seja, a mobilidade cotidiana tem que ser enxergada, também, como um meio de analisar a lógica social e política dos movimentos no espaço geográfico, de conectar os movimentos físicos com as relações de poder e de diferenciações no seio da sociedade.

Kaufmann, Bergman e Joye (2004) levam em consideração os deslocamentos e a distribuição espacial dos bens, das informações e das pessoas, ou seja, de entidades concretas (pessoas e bens) e de entidades abstratas (informações, normas, ideias). Advogam em favor de uma visão mais holística do conceito de mobilidade espacial, incorporando elementos como as possibilidades (o potencial de movimento), as competências e o capital, ou, ainda, a interação entre os atores, as estruturas e os contextos. Para realizar a conexão teórica entre a mobilidade espacial e a mobilidade social, os autores definem o conceito de "motility" como a capacidade dos bens, informações e pessoas serem móveis no espaço social e geográfico e a adaptação e apropriação destes, em função de circunstâncias particulares (KAUFMANN, BERGMAN e JOYE, 2004, p. 750). Uma vez definidos estes conceitos, a análise das práticas socioespaciais e das estratégias individuais ou de classe permite, através do espaço percebido da mobilidade cotidiana, compreender certos aspectos da fragmentação socioespacial.

\section{Práticas de mobilidade, diferenciações socioespaciais e mobilidade cotidiana}

O estudo das práticas espaciais ligado à esta dimensão do cotidiano (a mobilidade), exige uma análise empírica da apropriação e das estratégias dos indivíduos na sua vida cotidiana. A prática espacial pode ser definida como a diferença entre o espaço ideal e o espaço real. Nas palavras de Lefebvre (1974, p.48):

A competência e o desempenho espacial próprios a cada membro de esta sociedade só podem se apreciar empiricamente. A prática espacial "moderna" define-se então pela vida cotidiana de um HLM ${ }^{10}$ na periferia, caso-limite e significativo; o que não autoriza a deixar de lado as estradas e a aéreo-política.

As "estradas", ou em outras palavras, as estruturas e o espaço concebido, representam os meios disponíveis, enquanto é através das práticas espaciais - da mobilidade real, enxergada a partir da competência e das capacidades individuais - que o espaço percebido se compreende. Ou seja, além do espaço concebido, o estudo das práticas espaciais permite enxergar outras facetas dos processos de fragmentação socioespacial. Kaufmann, Bergman e Joye (2004) ressaltam a importância do conceito de motility em três escalas. Ao nível micro, a acessibilidade e a competência podem ser estudadas em termos de opções e condições de deslocamento, com relação às diversas

9 Tradução própria de: "caractérisé par la centralité des lieux d’emploi et de résidence et organisé autour de relations de proximité".

10 Para atualizar esta referência na realidade brasileira contemporânea, poderíamos trocar HLM (Habitation à Loyer Modéré) da época francesa, pelos conjuntos habitacionais do Programa MCMV -Minha Casa Minha Vida. 
variáveis como o dinheiro, o tempo, o nível educacional etc. Ao nível médio, a associação entre mobilidade social e espacial leva a estudar redes sociais ou familiares. Enfim, em um nível macro, a pesquisa deveria, segundo os autores, explorar as relações entre o nível nacional e a geopolítica para avaliar o quanto estas repercutem no contexto local.

A competência, que associamos ao espaço percebido, isto é, a capacidade real dos indivíduos deslocarem-se e tirarem benefício (ou não) do espaço concebido, interessa principalmente nas duas primeiras escalas. Os capitais e as práticas de mobilidade são ligados a estratégias de diferenciação social, ao mesmo tempo que são reflexo da estrutura das desigualdades e da sua reprodução. Neste sentido, as escolhas modais não são neutras e revelam relações sociais conflituosas, ou de dominação, entre grupos ou classes sociais. Segundo Diaz Olvera, Plat e Pochet (1998, p.104), as escolhas modais "dependem da procura de uma adequação entre necessidades de deslocamentos e meios disponíveis, apoiam-se também em processos de distinção social". Os autores defendem o conceito de hierarquia modal que esconde estratégias de distinção e de diferenciação socioespacial e que parece ser bastante relevante para a realidade brasileira. Assim, o automóvel, objeto típico da classe média brasileira segundo Vasconcellos (2014), tornou-se meio de transporte e objeto de distinção social e de dominação espacial. Para dar um exemplo, no município de Guarulhos (SP), o automóvel responde por 30\% do total das viagens, mas ocupa 96\% do espaço viário. Já os modos não-motorizados (a pé e de bicicleta) representam 34\% do total de deslocamentos, com apenas 1\% do espaço viário. (PREFEITURA DE GUARULHOS, 2019). No Brasil, o veículo individual privado, a despeito de uma "democratização" deste meio de transporte desde os anos 2000, continua sendo sinônimo de status social privilegiado, em que o usuário é considerado (e se considera) superior, não somente aos pedestres e ciclistas, mas também aos usuários de transporte coletivo. Esta distinção pelo modo de transporte é uma característica frequente na América Latina:

em que uma parte da população se desloca em carros confortáveis e relativamente rápido, enquanto outra é obrigada, em razões dos seus meios financeiros a se deslocar a pé, em bicicleta ou em transporte coletivo, frequentemente em péssimas condições em termos de rapidez, de conforto e de segurança (GOUËSET et,al, 2014).

Apesar das externalidades negativas - a cada ano, mais de 30.000 mortes são registradas no trânsito brasileiro - o uso do automóvel é ainda enxergado como um modo "seguro" de deslocamento e como fator de distinção social.

A esta distinção pelo modal somam-se outros elementos que influem sobre as decisões de mobilidade. Uma pesquisa de 2018 realizada em 380 domicílios (universo de 1138 pessoas) ${ }^{11}$, coordenada pelo autor, mostrou que, em $70 \%$ dos casos, a razão para não realizar um deslocamento desejado é o custo. Ou seja, não basta ter o transporte disponível se o bolso não permite.

Além disto, a insegurança, como realidade e como discurso, evidentemente influi sobre as decisões e as formas de mobilidade, apontando para processos fragmentários, especialmente na multiplicação de impedimentos para o acesso e o gozo amplo das populações periféricas aos (nos) centros das cidades. A repressão policial, por exemplo, das UPP (Unidades de Polícia Pacificadora) nas favelas do Rio de Janeiro, associada à marginalização e rebaixamento social (e racial), cria o clima bem formulado no livro Ninguém entra, ninguém sai: mobilidade urbana e direito à cidade no Complexo do Alemão (VELOSO e SANTIAGO, 2017). Bem além da disponibilidade das infraestruturas de transporte, os processos de opressão, de segregação e de exclusão de determinadas categorias 
da população, especialmente das favelas e das periferias, têm um grande impacto na mobilidade. Do outro lado da pirâmide social, esta mesma insegurança ou violência (postulada ou real) leva as populações abastadas a usarem mais o automóvel, considerado como mais seguro.

A competência que associamos ao espaço percebido centra-se na vida cotidiana dos indivíduos, nas suas possibilidades reais de usar os meios disponíveis e de ter acesso à cidade. As estratégias de diferenciação socioespacial relacionadas à mobilidade não são apenas ligadas à hierarquia pelo modo, mas também, as estratégias de "evitar o(s) outro(s)" (JIRÓN, 2010), participando de uma mobilidade fragmentada e da "não-relação" entre diferentes fragmentos da cidade, que raramente interagem ou se cruzam. Neste sentido, no contexto brasileiro, a insegurança - como realidade e/ou como discurso - parece influir diretamente nos processos de (i)mobilidade que reforçam a fragmentação socioespacial no sentido de dificultar os deslocamentos em si (o acesso a cidade) e de acirrar as dificuldades de convivência ou de "cruzamento" das diferentes classes sociais nos espaços públicos. A diferenciação pode criar uma sensação de se "sentir fora do lugar" (JIRÓN, 2010), uma certa "fobia urbana", e inibir a frequência de certos espaços, de pobres em espaços de ricos, e vice-versa. Ainda resta abordar a importância do espaço vivido, espaço de possibilidades e de resistência, e que existe a despeito ou em razão dos dois outros tipos de espaços que conformam essa triplicidade.

\section{O espaço vivido e o espaço diferencial: a mobilidade cotidiana como apropriação e resistência}

Como visto, as representações do espaço, abstratas, penetram e induzem as práticas sociais, espaciais e políticas e as relações entre pessoas e objetos. O espaço percebido, entretanto, isto é o plano das práticas espaciais, situa-se justamente nesta intersecção entre este espaço concebido e o espaço vivido. Este último corresponde aos espaços de representações, que "[...]mais vividos que concebidos, nunca se submetem a coerência, nem tampouco à coesão"12 (LEFEBVRE, 1974, p. 52).

Em outras palavras, é no espaço vivido que residem as contradições e as possibilidades de fugas e resistências ao espaço concebido, que tarde ou cedo ameaça explodir, justamente porque aspira a uma coerência e tenta organizar vidas e cotidianos que são muito mais complexos do que o racionalismo imposto. É ali, no plano da vida cotidiana, que emerge o espaço diferencial, que representa as possibilidades de criação, de apropriação e de resistência individuais ou coletivas, frente ao que é imposto:

\footnotetext{
a burguesia e o capitalismo já têm muitas dificuldades em dominar o seu produto e meio de dominação: o espaço. Não podem reduzir a prática (o prático-sensível, o corpo e a prática socioespacial) ao seu espaço abstrato ${ }^{13}$ (LEFEBVRE, 1974, p. 76).
}

Assim, o espaço diferencial, por um lado, permite identificar as diferenças frente às forças homogeneizadoras, e, por outro lado, distinguir, separar o que foi injustamente confundido ou homogeneizado; isto é, uma posição contra a fragmentação socioespacial, é, ao mesmo tempo, um método para capturá-la.

Nas palavras de Lefebvre (1974), a luta de classes possui uma capacidade diferenciadora que segura, ou impede, a completa homogeneização do espaço abstrato. Trazendo o terceiro elemento da definição do conceito de "motility" de Kaufmann, Bergman e Joye (2004), a apropriação remete à

12 Tradução própria de: « Vécus plus que conçus, ne s'astreignent jamais à la cohérence, pas plus que la cohésion ». 13 Tradução própria de: "La bourgeoisie et le capitalisme ont d'ores et déjà beaucoup de peine à dominer leur produit et leur moyen de domination: l'espace. Ils ne peuvent réduire la pratique (le pratico-sensible, le corps et la pratique socio-spatiale) à leur espace abstrait ». 
maneira como os agentes (indivíduos, grupos, redes ou instituições) interpretam e (re)agem com relação ao aspecto real e percebido do acesso e dos conhecimentos. A apropriação é justamente ligada ao espaço vivido, que através dos corpos, da construção das identidades e das práticas banais, deixa entrever uma possibilidade libertadora. Com relação à mobilidade cotidiana, evidentemente, o conceito de luta de classes foi (e precisa ser) readaptado, trazendo categorias como os de minorias ou de "movimentos de usuários", que representam de maneira mais expressiva as forças de resistências e as capacidades diferenciadoras.

\section{O "Mobility turn" e o espaço vivido da mobilidade cotidiana}

O Mobility Turn designa um momento em que a ciências sociais começaram a compreender o movimento como elemento estruturante da sociedade (SOJA, 2010; JIRÓN, 2010). Nesta visão, a mobilidade e o movimento deixam de significar apenas o deslocamento físico e adquirem um sentido social e simbólico para os indivíduos. Além da diminuição de distâncias, permitem criação de laços e de identidades. Importante, não obstante, ficarmos atentos aos possíveis exageros da ideia de compressão espaço-temporal, isto é, atribuir demasiada importância a "fluidificação" das estruturas sociais e dos movimentos das entidades concretas (pessoas, bens) e abstratas (informação, por exemplo) e em que os procedimentos humanos tradicionais de comunicação teriam sido negligenciados (MOLOTCH, 1994, apud KAUFMANN, BERGMAN e JOYE, 2004). Para a análise da fragmentação socioespacial, é útil compreender o sentido desta dicotomia entre o caráter opressivo e limitado da mobilidade e do acesso à cidade, por um lado, e as possibilidade de permanência de laços sociais territoriais não-diluídos e de estratégias subversivas ou criativas visando fugir de um cotidiano esvaziado.

Os movimentos físicos, que temos designado pelo termo mobilidade cotidiana, mas também os movimentos imaginários e as trocas virtuais e de informações, seriam, nesta concepção, espaços de liberdade, de construção das identidades. Os "transient places", isto é, os espaços transitórios, como os próprios meios de transporte, mas também as estações de transporte, as praças, mercados, ruas etc. podem ser opressivos, enxergados como "não-lugares" ou como sinônimos de perda de tempo, mas representam, para alguns indivíduos, momentos cruciais e essenciais na sua existência (JIRÓN, 2010). Assim é, porém, nas práticas de mobilidade reais do cotidiano - fortemente dominadas pelo espaço concebido - que existem os resíduos, as capacidades de produção, de criação e de apropriação do espaço. Assim, estas práticas:

[...] permiten visualizar el modo en que los límites de los fragmentos espaciales en los cuales la ciudad ha sido descompuesta son transgredidos por medio de la movilidad, reunificándose sus partes por medio de estrategias que permiten subvertir el orden impuesto por el urbanismo actual (JIRÓN e MANSILLA, 2014, p. 8).

Práticas subversivas de mobilidade e de contorno: a mobilidade como produção do espaço e diferença produzida

O termo "práticas subversivas de mobilidade", inspira-se no termo "mobilidades subversivas" (COHEN, COHEN e XIANG, 2017). Embora usado em outro contexto pelos autores ${ }^{14}$, como metáfora, pode aplicar-se às práticas cotidianas de mobilidade cujas características contornam, burlam, fogem

14 Os autores tratam de mobilidades que subvertem os sistemas de defesas dos regimes de mobilidade ao nível internacional, como a cocaína de Colômbia aos Estados Unidos ou os cornos de rinocerontes da África do Sul para o Vietnam. 
da alienação e do relativo controle das práticas pelo espaço abstrato. Isto consiste principalmente na apropriação e criação de espaços diferentes, como um ato ou movimento de resistir ao espaço abstrato, colocando o valor de uso acima do valor de troca, a qualidade por cima da quantidade, ou seja, por cima da dimensão simplória do deslocamento entre as caixinhas "organizadas" pelo Estado e seus planejadores e pelas forças econômicas da iniciativa privada.

Para a pesquisa empírica, trata-se de captar as práticas que vão no sentido contrário ao da fragmentação e alienação da vida cotidiana, as que desenvolvem, por exemplo, a socialização, o imprevisto, o jogo, o encontro, as pequenas costuras do cotidiano. Trata-se, no campo da mobilidade, de distinguir as diferenças induzidas e as diferenças produzidas (LEFEBVRE, 1974). As primeiras são as diferenças sugeridas ou impostas pelo espaço abstrato, que, desde o ponto de vista cultural se manifestam como pastiche (JAMESON, 1991) e como uma "pasteurização cultural, que nos torna espectadores dos acontecimentos e educa-nos para o consumo" (LIMONAD, 2000). As segundas representam diferenças no sentido de rompimentos e rupturas deste, constituem o espaço diferencial (LEFEBVRE, 1974). Neste aspecto, ao menos duas dimensões são essenciais para captar as possibilidades de apropriação/criação em uma análise da mobilidade e da fragmentação no escopo do espaço diferencial: o corpo e o tempo.

No que diz respeito às questões do corpo e da corporeidade, podem ser enxergados como instrumentos contra hegemônicos, apesar de que os corpos verdadeiros em movimento tenham sido desprezados pela agenda de estudos sobre transporte (CRESSWELL, 2010). Isto é válido para a realidade brasileira: em um levantamento baseada no sistema Qualis da CAPES, abrangendo o período de 1974 a 2013, apenas 38, em um total de 17.636 artigos na área de geografia mencionam o corpo como elemento de análise geográfica (SILVA, ORNAT e JUNIOR, 2019). No âmbito da mobilidade cotidiana, não obstante, identidades, histórias e resistências podem constituir um caminho para o espaço diferencial através da apropriação e da criação. No Rio de Janeiro, nos anos 1930, por exemplo, os sambistas que podiam ser presos pela lei da vadiagem, por tocar instrumentos na rua, começaram a tocar no trem que ia da Central do Brasil em direção aos subúrbios da zona norte, dando origem às maiores escolas de samba, como a estação primeira (a primeira partindo da Central) de Mangueira. Pular a catraca ou entrar pela porta de trás do ônibus, escolher andar de bicicleta apesar do risco que isto representa na maioria das cidades brasileiras, dançar no metrô, também podem ser consideradas práticas subversivas, para as quais o corpo tem uma importância crucial.

A complexidade da vida social e cotidiana está inscrita no corpo, nessa dialética entre o corpo e o espaço. Neste sentido, a apropriação do espaço e da vida passa por uma apropriação do corpo e por uma tentativa de extraí-lo do domínio, do controle, da fragmentação criados pelo poder hegemônico. Penetrar onde não se é esperado e/ou desejado já é, em si, colocar o seu corpo contra o espaço dos dominantes, à exemplo do fenômeno dos "rolezinhos ${ }^{15 "}$ nas grandes cidades brasileiras, dos "farofaços" nas praias cariocas da zona sul, ou ainda da "bicicleta como resistência" (ROSIN e LEITE, 2019) em São Paulo: práticas diferenciais que reafirmam os seus corpos no espaço com o valor de uso.

Tanto nos estudos de mobilidade quanto de fragmentação socioespacial, o tempo aparece como um elemento a ser resgatado na análise. Como lembra Lefebvre (1974, p. 411): "O uso reaparece em conflito agudo com troca no espaço, porque implica 'apropriação' e não 'propriedade'. Contudo, a própria apropriação implica tempo e tempos, ritmo e ritmos, símbolos ou uma prática". Jirón (2010)

15 Os "rolezinhos" ficaram famosos nos últimos anos. Trata-se de um fenômeno social e político em que os jovens de periferias se juntam para passear nos Shopping centers nos quais não são esperados. 
nota um esquecimento frequente das variáveis temporais, que, também fragmentadas, podem ajudar a explicar os processos de fragmentação socioespacial e também, um peso excessivo daquilo que é fixo, com relação ao movimento. O tempo que se passa em movimento, neste sentido, não pode apenas ser enxergado em termos de tempo perdido ou de tempo livre. Evidentemente, a predominância do trabalho no cotidiano e a fragmentação do tempo (controlado) dos indivíduos, pesam na vida cotidiana. Bem feliz quem tem frequentemente tempo de praticar o exercício de vagar pelas ruas sem rumo e de "deixar levar" seu próprio corpo aos encontros, imprevistos, intuições. Para a uma maioria avassaladora de pessoas, este tempo não existe, o que não quer dizer que o tempo seja sempre um tempo morto para as populações que passam horas diariamente nos serviços de transporte. Em uma entrevista realizada com uma jovem moradora do bairro periférico dos Pimentas (Guarulhos, SP) ${ }^{16}$, a entrevistada relatou uma parte da sua adolescência indo todos os dias na cidade de São Paulo para estudar, o que implicava no mínimo três horas por dia no ônibus, tempo que usava para ler bastante. Mais do que estas estratégias de superar um tempo a priori perdido, a criação de outros ritmos e tempos permite a apropriação de outros espaços, conjuntamente com a apropriação do corpo, para dar conteúdo e sentido ao cotidiano.

\section{Conclusão}

A abordagem do tema da mobilidade através do conceito de triplicidade do espaço (LEFEBVRE, 1974) e dos três pilares da definição de motility (KAUFMANN, BERGMAN e JOYE, 2004), permitiu percorrer suas diversas definições e visões, desde a mais tradicional e geral (transporte, estatísticas básicas sobre a mobilidade), até o que é chamado de "new mobilities paradigm" (CRESSWELL, 2010) que aporta uma visão menos estruturalista da mobilidade, interessando-se nas práticas reais de mobilidade e nas representações e construções de identidades que se formam nos movimentos, não apenas dos corpos e dos indivíduos, mas das ideias, das informações etc.

Entre a liberdade absoluta de movimento e a completa determinação dos movimentos pelo sistema dominante, existe uma infinidade de práticas de mobilidade. Evidentemente, o estudo das estruturas e infraestruturas de transporte, o peso do automóvel, o aumento das distâncias, dentre outros, são fatores que pesam e explicam, fisicamente, a forma e os processos de fragmentação socioespacial. Por outro lado, o método será incompleto, tanto para analisar a mobilidade cotidiana como os processos de fragmentação, se não há pesquisa empírica que capture as práticas reais e cotidianas dos indivíduos.

Estudos que pesquisam os movimentos e deslocamentos das mulheres e as questões de gênero na mobilidade (JIRÓN e GÓMES, 2018; SOTO, 2013) revelam-se um caminho promissor para trazer a questão dos ritmos, dos corpos, dos tempos e da opressão, que ainda precisam de muita pesquisa empírica, como estratégia para captar os processos contemporâneos de fragmentação socioespacial. As "mobilidades subversivas" apresentadas aqui, por exemplo, podem ainda parecer práticas pontuais e fragmentadas. Estas precisariam de estudos mais aprofundados e de maior sistematização para apreender, não somente a importância da (i)mobilidade nas cidades fragmentadas, mas, também aquela dos tempos e dos "homens lentos", ao mesmo tempo oprimidos e portando neles, pela mesma lentidão, uma capacidade de apropriação e de resistência (VIDAL, 2020).

16 Entrevista realizada pelo autor e uma colega no dia 18 de junho de 2020, com uma ex-moradora do bairro de Pimentas (Guarulhos-SP). 


\section{Referências}

ABREU, M. (1996). Evolução Urbana do Rio de Janeiro. Rio de Janeiro: IPLANRIO.

AND- Associação Nacional dos Detrans. 2017. Brasil já tem 1 carro a cada 4 habitantes, diz Denatran, 10 de março 2017. Disponível em: http://www.and.org.br/brasil-ja-tem-1-carro-a-cada-4-habitantesdiz-denatran/

ANTP - Associação Nacional de Transporte Público. 2017. Sistema de Informações da Mobilidade Urbana da Associação Nacional de Transporte Público, Simob, ANTP, Relatório geral.

BEYER, A. (2011). "L'échéance des Jeux Olympiques de 2016 et les stratégies de restructuration du transport métropolitain de Rio de Janeiro". Confins (Revue franco- brésilienne de géographie), vol. 12. CALDEIRA, T. (2000). Cidade de muros: crimes, segregação e cidadania em São Paulo. Editora 34/Edusp, $400 \mathrm{p}$.

CRESWELL, T. (2010). Towards a politics of mobility. Environment and Planning D: Society and Space, vol. 28, p. 17-31.

COHEN, E., COHEN, Scott., XIANG LI. (2017). Subversive Mobilities”. Applied Mobilities, 2:2, p. 115-133. DIAZ-OLVERA, L., PLAT, D., POCHET, P. (2005). La ville hors de portée ? Marche à pied, accès aux services et ségrégation spatiale en Afrique subsaharienne. Espaces population sociétés, 2005, 1, p.145-161.

DIAZ-OLVERA, L., PLAT, D., POCHET, P. (1998). Villes africaines au quotidien: mobilités quotidiennes et contraintes sociales à Bamako et Ouagadougou. Laboratoire d'Économie des Transports, Études et recherches, Lyon, 1998, $170 \mathrm{p}$.

DUHAU, E., GIGLIA, A. (2016). El orden metropolitano contemporáneo: entre la fragmentación y la interdependencia. In: Metrópoli, espacio público y consumo. México: Fondo de Cultura Económica, p. 27-62.

FIX, M. (2015). Mobilidade urbana e direito à cidade: uma entrevista com Lúcio Gregori sobre transporte coletivo e Tarifa Zero, RBEUR, v.17, n.3.

FLONNEAU, M., GUIGENO, V. et.al. (2009). De l'histoire des transports à l'histoire de la mobilité? Presses Universitaires de Rennes (PUR), $334 \mathrm{p}$.

GÓES, E., SPOSITO, M.E. (2016). Práticas espaciais, cotidiano e espaço público: o consumo como eixo da análise do calçadão de Presidente Prudente-SP. Revista da Associação Nacional de Pós-graduação e Pesquisa em Geografia (Anpege), p.39-65, v.12, n.19, jul-dez.

GOMIDE, A. (2003). Transporte urbano e inclusão social: elementos para políticas públicas, IPEA. Texto para discussão, n 960, p.1-34.

GOMIDE, A. (2006). Mobilidade urbana, iniquidade e políticas sociais. IPEA, políticas sociaisacompanhamento e análise, p.242- 250.

GOUËSET, V. (coord.). (2014). Parcourir la métropole. Pratiques de mobilités quotidiennes et inégalités socio- territoriales, p. 265-302, In: Dureau, Françoise., Lulle, Thierry., Souchaud Sylvain, Contreras, Yasna. (dir.), Mobilités et changements urbains. Bogotá, Santiago et São Paulo, Rennes, PUR, coll. Espace et territoires.

HIDALGO, R., BORSDORF, A. (2005). Barrios cerrados y fragmentación urbana en América Latina: Estudio de las transformaciones socioespaciales en Santiago de Chile (1990-2000). In: HIDALGO, R., TRUMPER \& BORSDORF (Eds). Transformaciones urbanas y procesos territoriales. Lecturas del nuevo dibujo de la ciudad latinoamericana. Santiago de Chile: Geolibros - Academia de Ciencias Austriaca y Okanagan University College. 
IPEA - Instituto de Pesquisa Econômica Aplicada. (2011). "Infraestrutura social e urbana no Brasil: subsídios para uma agenda de pesquisa e formulação de políticas públicas", comunicados do IPEA, $n^{\circ} 94,35 \mathrm{p}$.

JAMESON, F. (1991). El posmodernismo o la lógica cultural del capitalismo avanzado. Ediciones Paidos Ibérica, $117 \mathrm{p}$.

JIRÓN, P. (2010). Mobile Borders in Urban Daily Mobility Practices in Santiago de Chile. International Political Sociology, 4, p. 66-79.

JIRÓN, P., GÓMEZ, J. (2018). Interdependencia, ciudad y género desde las estrategias de movilidad en la ciudad de Santiago. Tempo Social, revista de sociologia da USP, v. 30, n.2.

JIRÓN, P., MANSILLA, P. (2014). Las consecuencias del urbanismo fragmentador en la vida cotidiana de habitantes de la ciudad de Santiago de Chile. Revista Eure, vol 40, n. 121. p. 05-28, set. 2014.

JIRÓN, P. (2010). Mobile Borders in Urban Daily Mobility Practices in Santiago de Chile. International Political Sociology, 4, p. 66-79.

KAUFMANN, V. (1999). Mobilité et vie quotidienne : synthèse et questions de recherches, Direction de la recherche et des affaires scientifiques et techniques du Ministère de l'équipement, des transports et du logement, Centre de prospective et de veille scientifique, 48, $61 \mathrm{p}$.

KAUFMANN, V., BERGMAN, M., JOYE, D. (2004). Motility: Mobility as Capital. International Journal of Urban and Regional Research, Vol.28.4, p.745-756.

LEFEBVRE, H. (1968) (1991). A vida cotidiana no mundo moderno. Editora Ática.

LEFEBVRE, H. (1970). La révolution urbaine. Gallimard.

LEFEBVRE, H. (1974) (4ème edition 2000). La production de l'espace, Anthropos.

LEGROUX, J. (2016). L'accueil de la coupe du Monde 2014 et de JO 2016 et les impacts de la « révolution des transports » sur la justice socio-spatiale à Rio de Janeiro : tout changer pour que rien ne change? Tese de doutorado em cotutela em Géographie, Aménagement, Urbanisme na Université de Lyon 2 (France) e no IPPUR na Universidade Federal do Rio de Janeiro, 435 p.

LEGROUX, J. (2019). A ressaca olímpica do transporte carioca. Uma reflexão sobre o estado da «revolução do transporte » no Rio de Janeiro. Anais do Congresso 20 Anos do Observatório das metrópoles, p.59-76.

LEIBLER, L., MUSSET, A. (2010). Un transporte hacia la justicia espacial? El caso del Metrocable y de la comuna nororiental de Medellín, Colombia. Scripta Nova, XIV, 331 (48), 14 p.

LEMOS, D., SANTOS, D., SILVA, L. (2004). Análise da relação entre o sistema de transporte e a exclusão social na cidade do Rio de Janeiro. Engesvista, 6(3), p.36- 53.

LÉVY, J., LUSSAULT, M. (2003). Dictionnaire de la géographie. Broché, 1033 p.

LIMONAD, E. (2000). A cidade na pós-modernidade: entre a ficção e a realidade. GEOgraphia, Ano II n.3, p.89-90.

LINARES, S. (2009). Fragmentación y segregación socioespacial: discutiendo categorías conceptuales para estudiar las desigualdades en ciudades medias. XII Encuentro de Geógrafos de América Latina, del 3 al 7 de abril de 2009, Montevideo, Uruguay.

MATELA, O. (2014). Transição regulatória no transporte por ônibus na cidade do Rio de Janeiro. Dissertação (Mestrado em Planejamento Urbano e Regional), IPPUR-UFRJ, Rio de Janeiro.

ORFEUIL, J.P. (2004). Transports, Pauvretés, Exclusions. Pouvoir bouger pour s'en sortir. Editions de l'aube, $180 \mathrm{p}$.

PAULO, CH. (2006). Inégalités de mobilité : disparité des revenus, hétérogénéité des effets. Thèse pour le Doctorat de Sciences Économiques mention Économie des Transports, Université Lumière Lyon 2, $383 p$. 
PEREIRA, R., BANISTER, D., SCHWANEN, T., WESSEL, N. (2019). Distributional effects of transport policies on inequalities in access to opportunities in Rio de Janeiro. The Journal of Transport and Land Use, vol. 12, n. 1[2019], pp, 741-764.

PEREIRA, R., GALINDO, E., VASCONCELLOS, E. (2011). A mobilidade urbana no Brasil: infraestrutura Social e Urbana no Brasil subsídios para uma agenda de pesquisa e formulação de políticas públicas. Comunicados do Ipea n.94, 25 de maio de 2011.

PREFEITURA DE GUARULHOS. (2019). Plano de Mobilidade Urbana de Guarulhos. Secretaria de Transporte e Mobilidade Urbana, maio 2019.

PRÉVÔT-SHAPIRA, M.F. (2001). Fragmentación espacial y social: conceptos y realidades. Perfiles latino-americanos. Revista de la Sede Académica de México de la Facultad latinoamericana de Ciencias Sociales.

RIBEIRO, L.C. RODRIGUES, J. (2013). Evolução da frota de automóveis e motos no Brasil: 2001-2012. Observatório das Metrópoles, Relatório, 40 p.

RORDRIGUES, J., BASTOS, P.P. (2016). State Action in Urban Transportation in the City of Rio de Janeiro: a reflection on the bus fleet rationalization". In: RIBEIRO, L-C., org. What is at stake in these Games: 2016 Olympics and the Commodification of the City of Rio de Janeiro, Observatório das Metrópoles.

ROSIN, L., LEITE, C. (2019). A bicicleta como resistência: o paradigma rodoviarista e o papel do ativismo ciclista no município de São Paulo/ SP. Cad. Metrop., São Paulo, v.21, n.46, pp.879-902, set/dez, 2019.

SANTOS, M. (1977). Sociedade e espaço: a formação social como teoria e como método. Boletim Paulista de Geografia, n.54.

SANTOS, M. (1990). Metrópole Corporativa Fragmentada: o caso de São Paulo. Editora da Universidade de São Paulo, $136 \mathrm{p}$.

SANTOS, M. (1996). A Natureza do Espaço: Técnica e tempo. Razão e emoção. Editora da Universidade de São Paulo.

SÉGUIN, A.M. (2011). Les quartiers: des lieux de fragmentation ? Cahiers de géographie du Québec, Vol. 55, n.154, avril.

SEN, A. (2011). A ideia de justiça. Editora Schwarcz Itda, 492 p.

SILVA, J., ORNAT, M., JUNIOR, A. (2019). O legado de Henri Lefebvre para a constituição de uma geografia corporificada. Caderno Prudentino de Geografia, n.41, v.3, p. 63-77, jul-dez.

SOJA, E. (2010). Seeking Spatial Justice. University of Minnesota Press.

SOUSA, G. (2019). Reestruturação Urbana em Resende-RJ: Análise das mudanças e manutenções provocadas pelos shopping centers no espaço de Resende-RJ. Espaço e Economia, 14, Ano VII.

SOTO, P (2013). Repensar las práticas espaciales: rupturas y continuidades em la experiência cotidiana de mujeres urbanas de la ciudad de México. Revista Latino-americana de Geografia e Gênero, Ponta Grossa, v.4, n.2, p. 2-12, ago/dez 2013.

SPOSITO, M.E., GÓES, E. (2013). Espaços fechados e cidades: Insegurança urbana e fragmentação socioespacial. Editora Unesp, 359 p.

SPOSITO, M.E. (2019). Fragmentação, Fragmentações. XVI Simpurb, 14 a 17 de novembro de 2019, Universidade Federal do Espírito Santos.

VASCONCELLOS, E. (2005). "Desvendando a política brasileira de mobilidade urbana", Revista dos Transportes Públicos, ANTP, Ano 27/28, 2005, 3\%/4 trimestre.

VASCONCELLOS, E. (2014). Políticas de transportes no Brasil: a construção da mobilidade excludente. Editora Manole, São Paulo, 289 p. 
VELOSO, S., SANTIAGO, V. (2017). Ninguém entre, ninguém sai: mobilidade urbana e direito à cidade no Complexo do Alemão. Fundação Heinrich Böll.

VIDAL, L. (1995). Les mots de la ville au Brésil. Un exemple: la notion de fragmentation. Cahiers des Amériques Latines, n.18, pp.161-181.

VIDAL, L. (2020). Les hommes lents: résister à la modernité, XVe-XXe siècle. Flammarion, 